\title{
Potency Unit
}

National Cancer Institute

\section{Source}

National Cancer Institute. Potency Unit. NCI Thesaurus. Code C48470.

The basic quantity or increment used to describe the strength of a product or amount of product in a package. 